\title{
Т.В. Теплова
}

Национальный исследовательский университет

«Высшая школа экономики», Москва

\section{Т.В. Соколова}

Национальный исследовательский университет «Высшая школа экономики», Москва

\section{А.С. Теплов}

Государственный университет управления, Москва

\section{Интемектуальный капитал российских компаний как Арайвер снижения стоимости долга ${ }^{1}$}

\begin{abstract}
Аннотация. Интеллектуальный капитал (ИК) в XXI в. рассматривается как потенциальный источник конкурентных преимуществ компаний и фактор увеличения их рыночной стоимости. Насколько значим на российском рынке ИК в снижении стоимости долга - это открытый вопрос. Работа посвящена выявлению показателей процессного и инновационного ИК, сигнализирующих о финансовых преимуществах использующих их компаний. Мы рассматриваем открытый и рыночный элемент долга - корпоративные облигации вторичного рынка. Выборка включает 299 наблюдений по 93 российским компаниям реального сектора в период с 2010 по 2015 г. Методология исследования регрессионный анализ с использованием несбалансированной панели данных. Эмпирическое исследование показало, что компании имеют возможность удешевить долг путем наращивания элементов ИК. Элементы ИК по-разному влияют на ставку публичного долга. Значимыми оказались показатели наличия нематериальных активов, размеры расходов на НИОКР, формирование команды управленцев, численность совета директоров. Наличие нематериальных активов (НМА) и увеличение числа патентов увеличивает доходность котируемых облигаций. Наличие НИОКР по российским компаниям является положительным сигналом для кредиторов - ставки котируемых облигаций снижаются. Оригинальный вывод нашего исследования - единоличное правление приводит к удорожанию публичного долга, а увеличение численности совета директоров - к выработке сбалансированной стратегии и распознается рыночными инвесторами, ставки по облигациям вторичного рынка котируемых облигаций становятся ниже.
\end{abstract}

Ключевые слова: интеллектуальный капитал, нематериальные активы, стоимость долга, рублевые корпоративные облигаиии, доходность облигаиий. Классификация JEL: O34, G12.

\section{Введение}

1980-1990 годы привлекли внимание академических исследователей к аномально высокой рыночной оценке ряда компаний (высокотехнологических и ИТ-компаний). Сформировалось целое направление изучения причин высокой оценки рыночными инвесторами этого феномена. Появилась концепция значимости интеллектуального капитала. Тем не менее до сих пор нет единого, общепризнанного понимания интеллектуального капитала (ИК) и формирующих его

\footnotetext{
${ }^{1}$ Статья подготовлена в ходе проведения исследования (№ 18-05-0007) в рамках Программы «Научный фонд Национального исследовательского университета «Высшая школа экономики» (НИУ ВШЭ)» в 2017-2018 гг. и в рамках государственной поддержки ведущих университетов Российской Федерации «5-100».
} 
элементов. Дискуссионными остаются положения о выгодах затрат на создание элементов ИК на уровне компаний реального сектора экономики.

Компании с высокой долей нематериальных активов (НМА), и в более широком плане - ИК, традиционно демонстрируют особенности в выборе финансовой стратегии - структуре капитала, структуре заемных источников финансирования - и в управлении денежными средствами (традиционно фиксируется большой запас эквивалентов денежных средств в активах баланса). Есть доказательства влияния ИК на рыночную стоимость бизнеса. Насколько наличие элементов ИК оказывает влияние на стоимость долга, открытый вопрос.

В зарубежной литературе исследовано влияние фундаментальных и нефундаментальных факторов на выбор источников финансирования и стоимость элементов капитала компаний. Так как затраты на капитал зависят от принимаемого владельцами элементов капитала компании риска, то акцент в анализе делается на раскрытие этих факторов и потенциальных механизмов их снижения. Кредитный риск зависит не только от объективной способности компании обслуживать взятые финансовые обязательства, но и от наличия агентских конфликтов. При определенных ситуациях ключевые собственники и топ-менеджмент могут стать мотивироваными в отказе от взятых обязательств, переносе убытков на других стейкхолдеров. Кредиторы, включая держателей публичного долга, не могут игнорировать эти намерения и возможности. По непубличному долгу в большинстве случаев защита кредитора выражается во введении различных ковенант, включая личные обязательства и гарантии со стороны ключевого собственника. Примером на российском рынке таких гарантий были личные соглашения ряда мажоритариев и управленцев банка перед VIPвкладчиками, например гарантии Г. Фетисова, владельца «Мой банк». По публичному долгу (облигациям) ковенанты более формальные и менее распространенные. Насколько ИК помогает компаниям снизить стоимость публичного долга, и какие элементы этого капитала распознают рыночные инвесторы на российском рынке - предмет исследования данной работы.

У успешно работающих компаний рыночная стоимость превышает балансовую. Мы исследуем источники этого превышения и выявляем роль элементов ИК в удешевлении заемного капитала. В нашей работе используется классификация элементов ИК, разработанная Л. Эдвинссоном (Эдвинссон, 2005). Мы рассматриваем процессный и инновационный ИК как элементы организационного (см. рисунок). К процессному ИК относится работа аудиторов, организация работы правления компании и состав совета директоров. К инновационному ИК - использование новых технологий, фиксируемое по доле НМА, наличию НИОКР, числу патентов на объекты интеллектуальной собственности и раскрытию информации об ИК. 

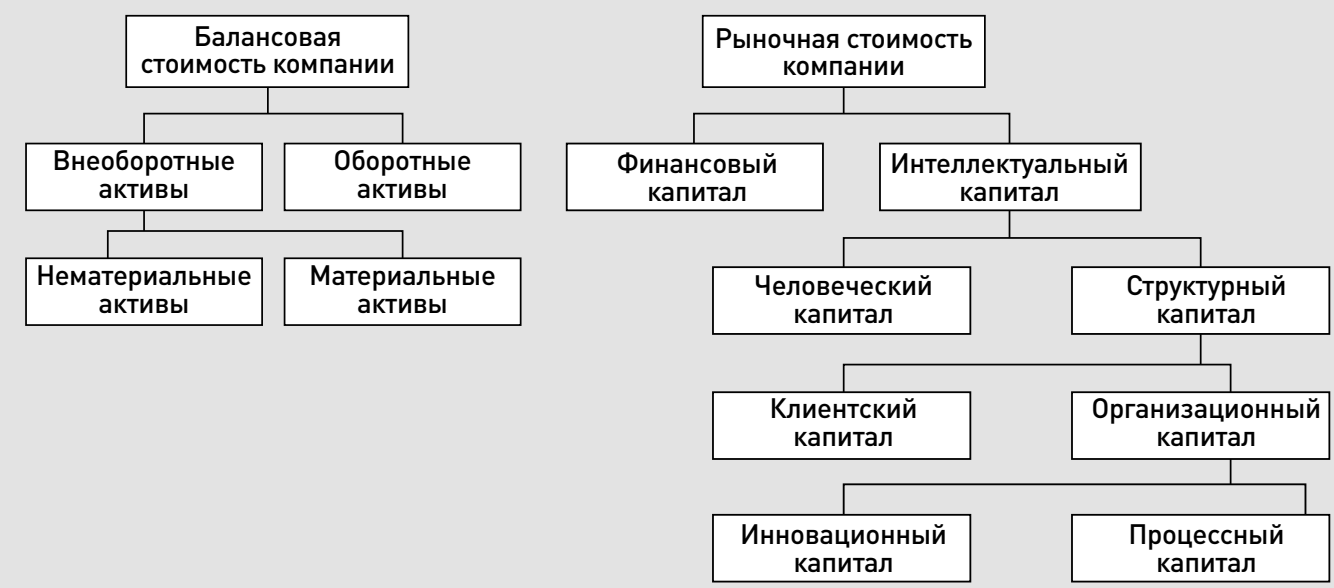

Рисунок

Балансовая и рыночная стоимость компании.

Классификачия элементов ИК дана согласно работе (Эдвинссон, 2005)

В рамках настоящего исследования мы рассматриваем диверсифицированную выборку компаний реального сектора экономики с обращающимися на бирже рублевыми облигациями и впервые анализируем влияние широкого спектра показателей ИК на доходность к погашению. В качестве элементов ИК мы рассматриваем компоненты процессного и инновационного капитала и эмпирически доказываем, что правильно выстроенная структура управления и принятия решений, аудита деятельности, политика раскрытия информации об элементах ИК позволяют снизить стоимость заимствования. Как результат, компании получают преимущества в увеличении рыночной стоимости.

\section{1. Обзор ранее проведенных работ по теме влияния элементов ИК на долг компании}

Первые работы по влиянию организационного ИК на стоимость компании шли по пути выделения расходов на НИОКР и взаимосвязи этих расходов с рыночной стоимостью (Griliches, 1984; Lev, Sougiannis, 1999; Hall et al., 2005). Традиционно цель деятельности компании формулируется в терминах увеличения рыночной стоимости. Результаты эмпирических тестирований взаимосвязи расходов на НИОКР со стоимостью компании неоднозначны: с одной стороны, НИОКР являются одним из ключевых факторов развития компании, будущих преимуществ на рынке, а с другой - авторы отмечают неспособность рыночных инвесторов учесть информацию о НИОКР в цене акций (Chan et al., 2001; Patel, Dallas, 2002).

Особенность исследования инновационного ИК - учет влияния собственно затрат, с одной стороны, а также факта раскрытия 
информации, с другой. Издержки раскрытия информации могут быть высокими. При этом можно рассматривать прямые издержки: на сбор, обработку и распространение информации - и косвенные издержки, которые прежде всего связаны с использованием раскрытой информации компаниями-конкурентами и потерей компанией конкурентных преимуществ (Lev, 1992; Macagnan, 2009).

На следующем этапе в исследованиях делался акцент на анализе влияния организационного ИК на такие элементы рыночной стоимости компании, как затраты на собственный капитал (Boujelbene, Affes, 2013; La Rosa, Liberatore, 2014) и средневзвешенные затраты на капитал (Iatridis, Senftlechner, 2014). Менее исследованы вопросы влияния организационного ИК на стоимость долга, так как даже публичный долг часто неликвиден и на вторичном рынке представлен межбанковскими сделками. Это существенно затрудняет проведение эмпирических исследований, так как анализ непубличных долгов должен базироваться на инсайдерской информации и может порождать искажения при переходе рассмотрения с одной компании на другую. Внутренний российский рынок котируемых облигаций (КО), напротив, характеризуется высокой долей биржевых торгов (свыше 90\%), что на сегодняшний момент позволяет выстроить полноценный эконометрический анализ влияния элементов ИК российских компаний на рыночную стоимость долга, определяемую как доходность к погашению по рублевым КО. Высока доля низколиквидных облигаций, и для формирования выборки мы проводили очищение с учетом уровня ликвидности.

В предыдущих работах не полностью раскрыты вопросы о том, насколько наличие элементов организационного (процессного и инновационного) ИК позволяет сгладить агентские конфликты между менеджерами, собственниками и кредиторами, какое влияние наличие элементов ИК оказывает на объемы привлечения долга и его стоимость.

Одним из важных факторов, определяющих положение компании на рынке и ее рыночную стоимость, является фиксация потенциала роста. Речь идет о производимых компаниями расходах на НИОКР (R\&D) и патентование новых разработок. В работах зарубежных авторов подчеркивается противоречивое влияние этих элементов организационного ИК на выбор источников финансирования и их дороговизну. В работе (Lev, 2001) показывается, что увеличение R\&D приводит к повышению расходов на обслуживание долга. Делается вывод, что для компаний с большой долей НМА доля долга должна быть ниже. Этот вывод подтверждается в работах (Alves, Martins, 2009, 2010) - высокий объем HMA и R\&D коррелируют с более низким уровнем долга. Одновременно авторы (Al-Najjar, Taylor, 2008; Salawu, Agboola, 2008) доказывают, что существует положительная корреляция между НМА и долгом. 
В работе (Chiao, 2002) на основе предложенной автором динамической модели и ее тестирования (выборка исследования включала свыше 20 тыс. наблюдений) показано, что в отраслях, не являющихся наукоемкими, долг является источником финансирования как инвестиций в основные фонды, так и в HMA через R\&D (R\&D и объем долга оказывают друг на друга положительное влияние). B наукоемких отраслях, напротив, долг является источником финансирования инвестиций только в материальные активы.

Таким образом, с одной стороны, элементы ИК (включая НМА) ограничивают объемы долгового финансирования, так как обладают низкой ликвидационной стоимостью и требуют премии за риск. С другой стороны, ИК может способствовать привлечению долгового финансирования, так как положительно влияет на динамику прибыли. Авторы (Liu, Wong, 2011) на выборке из 12743 наблюдений на отрезке с 1975 по 1999 г. приходят к выводу, что на американском рынке последний әффект превалирует. В работе (Wang et al., 2016) получен противоположный вывод. Авторы анализируют взаимосвязь между источниками финансирования, R\&D и риском банкротства, выраженным Z-коэффициентом Альтмана, для высокотехнологических компаний. На выборке из 553 компаний на периоде 2010-2014 гг. через построение линейных многофакторных регрессий показано, что чем выше $\mathrm{R} \& \mathrm{D}$, тем больше доля финансирования за счет собственных средств. Авторы объясняют полученный результат высокой процентной ставкой по заемным средствам для компаний с высокими расходами на $\mathrm{R} \& \mathrm{D}$.

C 2010-х годов в академических работах начинают подниматься вопросы не только о структуре капитала и заемных источников финансирования, но и о стоимости долга. В работе (Demeulemeester, Hottenrott, 2015) на основе анализа европейских компаний (461 наблюдение, 2000-2012 гг.) утверждается, что финансирование R\&D за счет займов, как правило, является дорогостоящим. Стоимость долга возрастает за счет асимметрии информации, неопределенности результата и низкой стоимости залога. Однако стоимость долга для компаний-получателей государственных субсидий на финансирование R\&D является более низкой, чем у компаний, не получивших такие субсидии. Метод исследования - регрессии с фиксированными әффектами по панельным данным. Результаты расчетов (Demeulemeester, Hottenrott, 2015) показали, что расходы на R\&D увеличивают стоимость долга. Число полученных патентов не является статистически значимым в объяснении его стоимости.

В работе (Loumioti, 2011) по выборке 1415 обеспеченных синдицированных кредитов, полученных американскими компаниями в период 1996-2005 гг, показано, что использование НМА в качестве залога значительно повышает процентную ставку по кредитам.

Еще одно направление исследований о взаимосвязи ИК и рыночной стоимости компании, дороговизны ее элементов капи- 
тала - анализ влияния раскрытия информации. Большая часть работ посвящена анализу взаимосвязи со стоимостью собственного капитала. Их результаты неоднозначны. В работах (Mangena et al., 2016; Boujelbene, Affes, 2013) показано, что чем выше прозрачность информации об ИК, тем ниже стоимость собственного капитала. Однако в работе (La Rosa, Liberatore, 2014) в этом плане не выявлена статистически значимая взаимосвязь. В работе (Orens et al., 2009) на основе анализа 267 нефинансовых европейских компаний по одному году утверждается, что более высокая степень прозрачности на основе интегрального индекса раскрытия информации об ИК по 42 категориям коррелирует с большей стоимостью компании и более низкими требуемыми доходностями по собственному и заемному капиталу. При этом метод расчета доходности по долгу вызывает сомнения. Ставка по заемному капиталу определялась в работе как отношение между процентными расходами за 2003 г. и суммой долгосрочного и краткосрочного долга на начало 2003 г.

В работе (Iatridis, Senftlechner, 2014) анализируется взаимосвязь между деловой репутацией (goodwill) и средневзвешенными затратами на капитал (WACC). Выборка включала все австрийские компании, представленные на Венской фондовой бирже в период с 2006 по 2011 г. Показано, что компании, обладающие goodwill и аудируемые представителями Big 4 (Ernst\&Young, KPMG, PwC, Deloitte), обладают более низкой оценкой WACC. B то же время компании, по которым наблюдается списание goodwill, демонстрируют более высокие значения WACC.

Ранние исследования взаимосвязи элементов организационного ИК и стоимости заемного капитала на российском рынке (Теплова, 2007; Милицкова, 2013; Теплова, Соколова, 2011) проводились на достаточно коротких временных рядах данных и не включали широкого спектра показателей инновационного и процессного ИК. В работе (Сувейка, 2015) акцент сделан на макроэкономических рисках с выделением глобальных и страновых факторов, а задача эконометрического анализа влияния элементов ИК на доходность по КО не ставилась.

Можно выделить следующие особенности ранее проведенных работ: 1) большинство исследований строится на анализе доходности новых выпусков облигаций (первичный рынок, как в работе (Милицкова, 2013)); 2) большая часть работ посвящена анализу рынков развитых стран, однако практически нет исследований динамики и по широкой выборке для российского рынка.

Вклад нашего исследования в эмпирическую литературу заключается в анализе влияния широкого спектра показателей инновационного и процессного ИК на стоимость заемного капитала на российском рынке. Наше исследование охватывает период после глобального финансового кризиса и основано на доступной для анализа выборке компаний реального сектора (93 компании). 


\section{2. Гипотезы и методы нашего исследования}

В нашем исследовании статистически проверяются следующие гипотезы.

Гипотеза 1. Наличие у компании большего процессного ИК, фиксируемого по таким показателям, как наличие признанного на рынке аудитора финансовой отчетности, наличие службы внутреннего аудита, большая численность совета директоров (СД), старший возраст членов СД, коллегиальное управление, снижает доходность по публичному долгу (рублевым КО).

Гипотеза 1 сформулирована на основе выводов ранее проведенных исследований по зарубежным рынкам (Iatridis, Senftlechner, 2014; Anderson et al., 2004; Johnson et al., 2013; Ashbaugh-Skaife et al., 2006). Обоснование выбора каждого элемента процессного ИК и направление влияния показано в табл. 1.

Гипотеза 2. Наличие у компании большего инновационного ИК, фиксируемого по таким показателям, как доля нематериальных активов (НМА) во внеоборотных и совокупных активах, размер расходов на НИОКР и их доля в активах, число патентов на объекты интеллектуальной собственности (ОИС), полнота раскрытия информации о расходах на НИОКР и патенты, снижает доходность по публичному долгу (рублевым КО).

Гипотеза 2 сформулирована на основе выводов ранее проведенных исследований по зарубежным рынкам (Martins, Alves, 2010; Loumioti, 2011; Orens et al., 2009; Demeulemeester, Hottenrott, 2015). Обоснование выбора каждого элемента инновационного ИК и направление влияния приведено в табл. 1.

В качестве контрольных переменных, объясняющих различия в доходности публичного долга, рассматриваются нефундаментальные и финансовые показатели компаний-эмитентов (доля государства в структуре акционерного капитала, выручка, покрытие EBIT процентных выплат (ICR), отношение чистого долга к EBIT) и характеристики облигационных займов (дюрация, включение в Ломбардный список). Выбор контрольных переменных проведен на основе результатов предыдущих исследований детерминант доходности облигаций на российском рынке (Teplova, Sokolova, 2015; Теплова, Соколова, 2011).

Для проверки гипотез применяются многофакторные линейные регрессии вида (1) по панельным данным. Объясняемые и объясняющие переменные показаны в табл. 1. Во всех регрессиях используется набор отраслевых дамми (в качестве базовой категории используется нефтегазовая отрасль как активный участник размещений публичного долга) и набор годовых дамми (базовым годом выступает 2011 г.).

Конечно, рассматриваемый нами список прокси-показателей ИК не является исчерпывающим, но мы постарались отразить те факторы, которые: 1) доступны в открытых источниках (отчетах компаний, базах данных), 2) часто используются в ранее проведенных ака- 
демических работах, 3) количественно измеримы и сопоставимы по компаниям различных отраслей.

Таблица 1

Список прокси-показателей ИК

\begin{tabular}{|c|c|c|c|}
\hline \multirow{2}{*}{$\begin{array}{l}\text { Обозначение } \\
\text { переменой }\end{array}$} & \multirow{2}{*}{ Описание переменной } & \multicolumn{2}{|c|}{$\begin{array}{l}\text { Ожидаемое направление влияния и обо- } \\
\text { снование выбора фактора }\end{array}$} \\
\hline & & Знак & Комментарий \\
\hline \multicolumn{4}{|c|}{ Объясняемые переменные } \\
\hline$L n_{-} Y T M$ & $\begin{array}{l}\text { Логарифм YTM, средневзвешен- } \\
\text { ной по объему обращающихся } \\
\text { займов компании-эмитента (в } \\
\text { период с } 15 \text { апреля по } 15 \text { мая) }\end{array}$ & & \\
\hline Ln_Spread & $\begin{array}{l}\text { Логарифм спреда } Y T M \text { к безри- } \\
\text { сковой ставке }\end{array}$ & & \\
\hline \multicolumn{4}{|c|}{$\begin{array}{c}\text { Объясняющие переменные, характеризующие инновационный ИК компании } \\
\text { и раскрытие информации о нем }\end{array}$} \\
\hline int_noncur & $\begin{array}{l}\text { Доля } H M A \text { во внеоборотных } \\
\text { активах, \% }\end{array}$ & \multirow{4}{*}{+} & \multirow{4}{*}{$\begin{array}{l}\text { В работе (Martins, Alves, 2010) пока- } \\
\text { зано, что кредиторы требуют более } \\
\text { высокие премии по займам для } \\
\text { фирм, интенсивно использующим } \\
\text { HМА. } \\
\text { (Loumioti, 2011) пришел к выводу, } \\
\text { что использование НМА в качестве } \\
\text { залога по синдицированным кре- } \\
\text { дитам значительно повышает про- } \\
\text { центную ставку по кредитам }\end{array}$} \\
\hline $\begin{array}{l}\text { int_noncur_ } \\
\text { dummy }\end{array}$ & $\begin{array}{l}\text { Признак того, является ли доля } \\
\text { НМА во внеоборотных активах } \\
\text { положительной: } \\
0-\text { нулевая доля, } \\
1 \text { - положительная }\end{array}$ & & \\
\hline int_assets & $\begin{array}{l}\text { Доля НМА в совокупных акти- } \\
\text { вах, \% }\end{array}$ & & \\
\hline $\begin{array}{l}\text { int_assets_ } \\
\text { dummy }\end{array}$ & $\begin{array}{l}\text { Признак того, является ли доля } \\
\text { НМА в совокупных активах поло- } \\
\text { жительной: } \\
0 \text { - нулевая доля, } \\
1 \text { - положительная }\end{array}$ & & \\
\hline$R D \_d a t a$ & $\begin{array}{l}\text { Признак того, раскрыты ли } \\
\text { в отчетности данные по расхо- } \\
\text { дам на НИОКР за год: } 0-\text { нет, } \\
1 \text { - да }\end{array}$ & - & $\begin{array}{l}\text { (Orens et al., 2009) показали, что } \\
\text { большая степень раскрытия дан- } \\
\text { ных об интеллектуальном капитале } \\
\text { коррелирует с более низкой стои- } \\
\text { мостью собственного и заемного } \\
\text { капитала }\end{array}$ \\
\hline RD_to_Revenue & Расходы на НИОКР к выручке & \multirow{2}{*}{\multicolumn{2}{|c|}{$\begin{array}{l}\text { (Demeulemeester, Hottenrott, 2015) } \\
\text { показали, что финансирование } \\
\text { R\&D за счет кредитов, как правило, } \\
\text { является дорогостоящим в связи } \\
\text { с асимметрией информации и нео- } \\
\text { пределенностью результатов. } \\
\text { Результаты расчетов } \\
\text { (Demeulemeester, Hottenrott, 2015) } \\
\text { показали, что расходы на R\&D уве- } \\
\text { личивают ставку по долгу }\end{array}$}} \\
\hline$R D \_d u m m y$ & $\begin{array}{l}\text { Признак того, осуществляет ли } \\
\text { компания расходы на НИОКР: } \\
0 \text { - нет, } 1 \text { - да }\end{array}$ & & \\
\hline patent_data & $\begin{array}{l}\text { Признак того, раскрыто ли } \\
\text { в отчетности количество патен- } \\
\text { тов на конец года: } 0 \text { - нет, } 1 \text { - да }\end{array}$ & - & $\begin{array}{l}\text { (Orens et al., 2009) показали, что } \\
\text { большая степень раскрытия дан- } \\
\text { ных об интеллектуальном капитале } \\
\text { коррелирует с более низкой стои- } \\
\text { мостью собственного и заемного } \\
\text { капитала }\end{array}$ \\
\hline
\end{tabular}


Продолжение таблицы 1

\begin{tabular}{|c|c|c|c|}
\hline \multirow{2}{*}{$\begin{array}{c}\text { Обозначение } \\
\text { переменой }\end{array}$} & \multirow[t]{2}{*}{ Описание переменной } & \multicolumn{2}{|c|}{$\begin{array}{c}\text { Ожидаемое направление влияния и обо- } \\
\text { снование выбора фактора }\end{array}$} \\
\hline & & Знак & Комментарий \\
\hline $\begin{array}{l}\text { patents_to_ } \\
\text { intangibles }\end{array}$ & $\begin{array}{l}\text { Отношение количества патен- } \\
\text { тов на ОИС (полезных моделей, } \\
\text { изобретений, программ, про- } \\
\text { мышленных образцов, за исклю- } \\
\text { чением товарных знаков) к вели- } \\
\text { чине НМА }\end{array}$ & \multirow{4}{*}{+} & \multirow{4}{*}{$\begin{array}{l}\text { В работе (Martins, Alves, 2010) пока- } \\
\text { зано, что кредиторы требуют более } \\
\text { высокие премии по займам для } \\
\text { фирм, интенсивно использующим } \\
\text { НМА }\end{array}$} \\
\hline $\begin{array}{l}\text { patents_to_ } \\
\text { noncur }\end{array}$ & $\begin{array}{l}\text { Отношение количества патентов } \\
\text { на ОИС к величине внеоборот- } \\
\text { ных активов }\end{array}$ & & \\
\hline $\begin{array}{l}\text { patents_to_ } \\
\text { total_assets }\end{array}$ & $\begin{array}{l}\text { Отношение количества патентов } \\
\text { на ОИС к величине совокупных } \\
\text { активов }\end{array}$ & & \\
\hline patent_dummy & $\begin{array}{l}\text { Дамми-переменная наличия } \\
\text { патентов на ОИС: } 0 \text { - отсутствие } \\
\text { патентов, } 1 \text { - есть патенты }\end{array}$ & & \\
\hline \multicolumn{4}{|c|}{ Объясняющие переменные, характеризующие процессный ИК } \\
\hline $\begin{array}{c}\text { audit } \\
(0,1,2)\end{array}$ & $\begin{array}{l}\text { Дамми-переменные, характеризу- } \\
\text { ющие выбор аудиторов финансо- } \\
\text { вой отчетности (МСФО и РСБУ): } \\
\text { 0 - отсутствуют аудиторы из } \\
\text { Big4 (KPMG, Ernst\&Young, } \\
\text { Price Waterhouse Coopers, } \\
\text { Deloitte and Touche); } 1 \text { - один из } \\
\text { аудиторов из Big4; } 2 \text { - все ауди- } \\
\text { торы из Big4 }\end{array}$ & - & $\begin{array}{l}\text { (Iatridis, Senftlechner, 2014) пока- } \\
\text { зали, что компании, обладающие } \\
\text { goodwill и аудируемые представи- } \\
\text { телями Big } 4 \text { (Ernst\&Young, KРMG, } \\
\text { PwC, Deloitte and Touche), обла- } \\
\text { дают более низкой стоимостью } \\
\text { капитала }\end{array}$ \\
\hline internal_audit & $\begin{array}{l}\text { Признак наличия службы вну- } \\
\text { треннего аудита: } 0 \text { - нет, } 1 \text { - да }\end{array}$ & - & $\begin{array}{l}\text { Внутренний аудит потенциально } \\
\text { ограничивает оппортунизм менед- } \\
\text { жмента и может снизить стоимость } \\
\text { займов }\end{array}$ \\
\hline directors & Число членов совета директоров & $-/+$ & $\begin{array}{l}\text { (Anderson et al., 2004) показал } \\
\text { наличие отрицательной взаимос- } \\
\text { вязи между числом членов совета } \\
\text { директоров и стоимостью займов, } \\
\text { тогда как (Lorca et al., 2011) выявил } \\
\text { нелинейную зависимость между } \\
\text { данными факторами }\end{array}$ \\
\hline directors_young & $\begin{array}{l}\text { Число членов совета директоров } \\
\text { в возрасте младше } 35 \text { лет }\end{array}$ & + & $\begin{array}{l}\text { В работе (Johnson et al., 2013) пока- } \\
\text { зано, что более молодой возраст } \\
\text { членов совета директоров спо- } \\
\text { собствует принятию риска (тогда } \\
\text { как старший возраст - избеганию } \\
\text { риска), а следовательно, стоимость } \\
\text { займов в этом случае повышается }\end{array}$ \\
\hline
\end{tabular}


Продолжение таблицы 1

\begin{tabular}{|c|c|c|c|}
\hline \multirow{2}{*}{$\begin{array}{l}\text { Обозначение } \\
\text { переменой }\end{array}$} & \multirow{2}{*}{ Описание переменной } & \multicolumn{2}{|c|}{$\begin{array}{c}\text { Ожидаемое направление влияния и обо- } \\
\text { снование выбора фактора }\end{array}$} \\
\hline & & Знак & Комментарий \\
\hline board & Число членов правления & \multirow{2}{*}{\multicolumn{2}{|c|}{$\begin{array}{l}\text { Единоличное управление потен- } \\
\text { циально может усилить агентские } \\
\text { конфликты между собственниками } \\
\text { и CEO. } \\
\text { (Ashbaugh-Skaife et al., 2006) пока- } \\
\text { зали, что механизмы управления, } \\
\text { способствующие улучшению про- } \\
\text { цесса принятия управленческих } \\
\text { решений и ограничивающие } \\
\text { оппортунистическое поведение } \\
\text { менеджеров, также приносят } \\
\text { выгоду и кредиторам }\end{array}$}} \\
\hline CEO_power & $\begin{array}{l}\text { Дамми-переменная коллегиаль- } \\
\text { ного управления: } 0 \text { - управление } \\
\text { осуществляется единолично, } 1 \text { - } \\
\text { коллегиальное управление }\end{array}$ & & \\
\hline $\begin{array}{c}\text { committee }_{-} \\
\text {compensation } \\
\text { data }(0,1,2,3)\end{array}$ & $\begin{array}{l}\text { Переменная, характеризующая } \\
\text { раскрытие информации о коми- } \\
\text { тете по вознаграждениям совета } \\
\text { директоров: } 0 \text { - информация не } \\
\text { раскрывается; } 1 \text { - отсутствует } \\
\text { комитет по вознаграждениям; } \\
2 \text { - комитет по вознаграждениям } \\
\text { существует; } 3 \text { - раскрыт состав } \\
\text { комитета по вознаграждениям }\end{array}$ & - & $\begin{array}{l}\text { Большая численность членов коми- } \\
\text { тета по вознаграждениям обеспе- } \\
\text { чивает более сбалансированную } \\
\text { политику выплат топ-менеджерам, } \\
\text { согласованную с интересами соб- } \\
\text { ственников. Это уменьшает агент- } \\
\text { ские конфликты между менедже- } \\
\text { рами и собственниками }\end{array}$ \\
\hline \multicolumn{4}{|c|}{ Контрольные переменные } \\
\hline gov & $\begin{array}{l}\text { Доля государства в собственном } \\
\text { капитале, \% }\end{array}$ & \multirow{2}{*}{\multicolumn{2}{|c|}{$\begin{array}{l}\text { С возрастанием доли государства } \\
\text { в структуре собственности снижа- } \\
\text { ются риски банкротства эмитента } \\
\text { облигации, следовательно, можно } \\
\text { ожидать более низкой доходности } \\
\text { к погашению (Теплова, Соколова, } \\
2011) \text { Полный контроль государ- } \\
\text { ства несет риски решения государ- } \\
\text { ственных задач за счет денежных } \\
\text { средств компании }\end{array}$}} \\
\hline gov2 & $\begin{array}{l}\text { Квадрат переменной gov (для } \\
\text { моделирования нелинейных } \\
\text { зависимостей доходности по КО } \\
\text { и ее спреда к безрисковой ставке } \\
\text { от доли государства) }\end{array}$ & & \\
\hline Sector_Dummy & $\begin{array}{l}\text { Дамми-переменные отрасли эми- } \\
\text { тента КО (для моделей с фикси- } \\
\text { рованными эффектами) }\end{array}$ & $+/-$ & \\
\hline Year_Dummy & $\begin{array}{l}\text { Дамми-переменные отдельных } \\
\text { лет - 2011-2016 гг. (для моделей } \\
\text { с фиксированными әффектами) }\end{array}$ & $+/-$ & \\
\hline dcrisis & $\begin{array}{l}\text { Дамми-переменная кризиса } \\
\text { в экономике России, отражает } \\
\text { повышение ключевой ставки } \\
\text { Банка России в 2015-2016 гг. }\end{array}$ & + & $\begin{array}{l}\text { Повышение ключевой ставки Банка } \\
\text { России приводит к росту ставок } \\
\text { кредитования }\end{array}$ \\
\hline Ln_Dur & $\begin{array}{l}\text { Логарифм дюрации облигацион- } \\
\text { ных займов, средневзвешенной } \\
\text { по объему обращающихя зай- } \\
\text { мов компании-эмитента }\end{array}$ & $+/-$ & $\begin{array}{l}\text { Направление связи зависит от } \\
\text { срочной структуры процентных } \\
\text { ставок, складывающихся на рынке }\end{array}$ \\
\hline Lombard & $\begin{array}{l}\text { Признак включения корпоратив- } \\
\text { ных рублевых облигаций эми- } \\
\text { тента в ломбардный список ЦБ } \\
\text { РФ (1 - да, } 0-\text { нет) }\end{array}$ & - & $\begin{array}{l}\text { В работе (Teplova, Sokolova, 2015) } \\
\text { показано, что включение облига- } \\
\text { ций в Ломбардный список снижает } \\
\text { YТМ и спред }\end{array}$ \\
\hline
\end{tabular}


Окончание таблицы 1

\begin{tabular}{|c|c|c|c|}
\hline \multirow{2}{*}{$\begin{array}{l}\text { Обозначение } \\
\text { переменой }\end{array}$} & \multirow{2}{*}{ Описание переменной } & \multicolumn{2}{|c|}{$\begin{array}{c}\text { Ожидаемое направление влияния и обо- } \\
\text { снование выбора фактора }\end{array}$} \\
\hline & & Знак & Комментарий \\
\hline N_Payments & $\begin{array}{l}\text { Число купонных выплат в год } \\
\text { (медиана по облигационным } \\
\text { выпускам эмитента) }\end{array}$ & - & $\begin{array}{l}\text { Исходя из формулы расчета цены } \\
\text { облигации, чем чаще происходят } \\
\text { выплаты, тем выше цена облигации } \\
\text { и ниже YTM }\end{array}$ \\
\hline Ln_Sales & Логарифм выручки & \multirow{3}{*}{-} & \multirow{3}{*}{$\begin{array}{l}\text { При увеличении размера предпри- } \\
\text { ятия можно ожидать положитель- } \\
\text { ного влияния эффекта масштаба } \\
\text { на рентабельность, а также дивер- } \\
\text { сификации деятельности компа-- } \\
\text { нии, что способствует повышению } \\
\text { финансовой устойчивости и сни- } \\
\text { жает ставку по займам }\end{array}$} \\
\hline $\begin{array}{l}\text { Ln_Sales_ } \\
\text { median }\end{array}$ & $\begin{array}{l}\text { Разность логарифма выручки } \\
\text { компании-эмитента и меди- } \\
\text { анного значения логарифма } \\
\text { выручки по компаниям соответ- } \\
\text { ствующей отрасли (для каждого } \\
\text { года) }\end{array}$ & & \\
\hline Ln_Assets & Логарифм совокупных активов & & \\
\hline NetDebt_EBIT & Отношение чистого долга к ЕВIT & + & $\begin{array}{l}\text { В работе (Теплова, Соколова, 2011) } \\
\text { показано, что при росте показате- } \\
\text { лей долговой нагрузки повышается } \\
\text { YTM }\end{array}$ \\
\hline$I C R$ & $\begin{array}{l}\text { Коэффициент покрытия EBIT } \\
\text { процентных выплат }\end{array}$ & - & $\begin{array}{l}\text { В работе (Теплова, Соколова, 2011) } \\
\text { показано, что при росте показате- } \\
\text { лей долговой нагрузки повышается } \\
\text { YTM }\end{array}$ \\
\hline
\end{tabular}

В качестве зависимых переменных используются только $L n \_Y T M$ и Ln_Spread, так как остатки в регрессиях YTM и Spread (т.е. нелогарифмированных переменных) демонстрируют гетероскедастичность. Основные расчеты проводятся после преобразования, смягчающего проблему мультиколлинеарности переменных. Так, вместо Ln_Sales используется переменная Ln_Sales_median, рассчитываемая как отклонение $L n \_S a l e s$ от медианного значения по соответствующей отрасли в соответствующем году.

Поскольку многие объясняющие переменные имеют наблюдения с нулевыми значениями, при логарифмировании их значение увеличивалось на минимальный уровень по выборке (см. табл. 1). Из-за наличия большого числа нулевых значений по ряду переменных (int_noncur, int_assets, RD_to_Revenue, patents_to_intangibles, patents_to_noncur, patents_to_assets) добавлены дамми-переменные, принимающие в таких случаях значение 0 , и значение 1 - во всех прочих. Нефундаментальные факторы сначала добавлялись к набору контрольных переменных по одному. На следующем этапе значимые переменные включались в уравнение регрессии совместно.

В нашем исследовании осуществляется построение линейных многофакторных регрессионных моделей (в векторной форме):

$$
\begin{gathered}
\ln (\text { Bond RETURN })=\alpha+\sum_{k} \beta_{1, k} \text { InnovativeIC }_{k}+\sum_{l} \beta_{2, l} \text { ProcessIC }_{l}+ \\
+\sum_{m} \beta_{3, m} \text { ControlVariable }_{m}+\varepsilon,
\end{gathered}
$$


где Bond RETURN - доходность облигации к погашению (YTM), или спред к безрисковой ставке; Innovative $I C_{k}-$ одна или несколько переменных, характеризующих инновационный ИК компании и раскрытие информации о нем; Process $I C_{l}$ - одна или несколько переменных, характеризующих процессный ИК и раскрытие информации о нем; ControlVariable $_{m}$ - одна или несколько контрольных переменных (нефундаментальные и финансовые показатели компаний), характеристики облигационных выпусков.

\section{3. Данные для исследования}

В выборку нашего исследования включались компании-эмитенты КО, относящиеся к реальному сектору экономики: машиностроительные, нефтегазовые, энергетические, металлургические, пищевые и торговые компании. Необходимым условием для включения в выборку являлось наличие у компании рублевых корпоративных облигаций, обращающихся на Московской бирже (МБ) с 15 апреля по 15 мая каждого года в период 2011-2016 гг., с ненулевым объемом торгов (т.е. займы, по которым фиксировалось только индикативная доходность к погашению (YTM), исключались). Выбранный период является периодом публикации годовой отчетности, что позволяет учесть влияние на YTM финансовых и нефундаментальных показателей, фиксирующих состояние компании на конец предыдущего года. Из выборки были исключены займы компаний, созданных исключительно для обеспечения финансовой деятельности головной компании (SPV).

Источником данных по рублевым облигационным выпускам стала база Cbonds, по финансовым и нефундаментальным показателям российских компаний-эмитентов - финансовая отчетность (по стандартам МСФО и РСБУ), годовые и ежеквартальные отчеты.

Итоговая выборка исследования содержит 299 наблюдений по 93 эмитентам рублевых облигаций за 2010-2015 гг. Отметим, что на облигационный рынок выходят преимущественно крупные компании реального сектора. Поэтому в нашей выборке медианная выручка по 2015 г. составила 72,5 млрд руб., наименьшая выручка по 2015 г. 0,5 млрд руб.

В табл. 2 представлены средние и медианные значения, а также стандартные отклонения объясняемых и объясняющих переменных. В качестве безрисковой ставки выбрана ставка по ГКО-ОФЗ соответствующей дюрации.

В табл. 3 показана доля участия государства в собственном капитале по компаниям выборки. Машиностроительные, нефтегазовые и энергетические компании характеризуются сравнительно высокой долей участия, тогда как металлургические, пищевые и торговые компании - преимущественно частные.

В табл. 4 показана доля НМА во внеоборотных активах по компаниям выборки. Средняя доля НМА во внеоборотных активах 
таблица 2

Средние и медианные значения, стандартные отклонения переменных по выборке в целом

\begin{tabular}{|c|c|c|c|}
\hline Переменная & Среднее значение & Медиана & Стандартное отклонение \\
\hline$Y T M, \%$ & 10,55 & 9,70 & 3,25 \\
\hline Spread, \% & 3,22 & 2,57 & 2,59 \\
\hline$L n \_Y T M$ & 2,31 & 2,27 & 0,29 \\
\hline Ln_Spread & 0,92 & 0,95 & 0,78 \\
\hline$L N \_D u r$ & $-0,06$ & 0,11 & 0,96 \\
\hline LN_Sales & 18,14 & 18,06 & 1,89 \\
\hline gov & 0,24 & 0 & 0,33 \\
\hline NetDebt_EBIT & 5,55 & 3,08 & 6,30 \\
\hline ICR & 5,88 & 2,90 & 7,51 \\
\hline Lombard & 0,62 & 1,00 & 0,49 \\
\hline N_Payments & 2,05 & 2,00 & 0,39 \\
\hline audit & 1,10 & 1,00 & 0,83 \\
\hline int_noncur & 0,09 & 0,02 & 0,15 \\
\hline int_assets & 0,05 & 0,01 & 0,09 \\
\hline$R D \_d a t a$ & 0,76 & 1 & 0,43 \\
\hline$R D \_d u m m y$ & 0,47 & 0 & 0,50 \\
\hline$R D \_t o \_R e v e n u e$ & 0,36 & 0 & 1,21 \\
\hline patent_data & 0,73 & 1 & 0,45 \\
\hline patents_to_intangibles & 46,23 & 0,08 & 122,52 \\
\hline patents_to_noncur & 1,28 & 0,004 & 3,96 \\
\hline patents_to_assets & 0,59 & 0,005 & 1,88 \\
\hline patent_dummy & 0,51 & 1 & 0,50 \\
\hline directors & 8,47 & 9 & 3,67 \\
\hline board & 5,73 & 5 & 4,91 \\
\hline CEO_power & 0,59 & 1 & 0,49 \\
\hline committee_compensation_data & 2,09 & 3 & 1,09 \\
\hline charity & 0,74 & 1 & 0,44 \\
\hline
\end{tabular}

наиболее высока в машиностроении (выше 14\% в период 20102015 гг.), а наиболее низка - в нефтяных и энергетических компаниях (ниже 3\% в период 2010-2015 гг.). Для всех рассматриваемых отраслей средняя доля НМА во внеоборотных активах по компаниям выборки не превышает 27\% (т.е. преобладают другие категории внеоборотных активов - основные средства, долгосрочные финансовые вложения). 
Таблица 3

Средняя и медианная доля участия государства в собственном капитале по компаниям выборки (2010-2015 гг.), \%

\begin{tabular}{|c|c|c|c|c|c|c|c|c|c|c|c|c|}
\hline \multirow[b]{2}{*}{ Отрасль } & \multicolumn{2}{|c|}{2010} & \multicolumn{2}{|c|}{2011} & \multicolumn{2}{|c|}{2012} & \multicolumn{2}{|c|}{2013} & \multicolumn{2}{|c|}{2014} & \multicolumn{2}{|c|}{2015} \\
\hline & 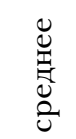 & 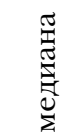 & 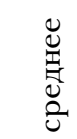 & 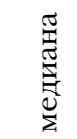 & 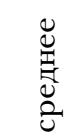 & 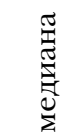 & 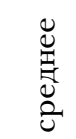 & 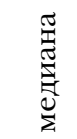 & 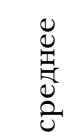 & 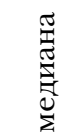 & 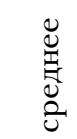 & 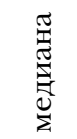 \\
\hline $\begin{array}{l}\text { Машино- } \\
\text { строение }\end{array}$ & 38,4 & 33,5 & 50,8 & 61,5 & 50,0 & 60,8 & 64,1 & 89,0 & 47,0 & 49,9 & 78,1 & 92,8 \\
\hline Нефтяная & 20,3 & 19,0 & 17,8 & 5,6 & 26,4 & 16,3 & 26,8 & 0,0 & 39,1 & 46,9 & 52,7 & 59,4 \\
\hline Энергетика & 29,4 & 22,9 & 27,7 & 22,9 & 39,3 & 27,9 & 33,7 & 34,1 & 42,5 & 43,3 & 47,1 & 57,1 \\
\hline $\begin{array}{l}\text { Черная } \\
\text { металлургия }\end{array}$ & 0 & 0 & 0 & 0 & 0 & 0 & 0 & 0 & 0 & 0 & 1,4 & 0 \\
\hline $\begin{array}{l}\text { Пищевая } \\
\text { и АПК }\end{array}$ & 0 & 0 & 0 & 0 & 0 & 0 & 0 & 0 & 0 & 0 & 0 & 0 \\
\hline Торговля & 0 & 0 & 5 & 0 & 1,6 & 0 & 1,4 & 0 & 0 & 0 & 0 & 0 \\
\hline
\end{tabular}

Таблица 4

Средняя и медианная доля НМА во внеоборотных активах по компаниям выборки (2010-2015 гг.), \%

\begin{tabular}{|c|c|c|c|c|c|c|c|c|c|c|c|c|}
\hline \multirow[b]{2}{*}{ Отрасль } & \multicolumn{2}{|c|}{2010} & \multicolumn{2}{|c|}{2011} & \multicolumn{2}{|c|}{2012} & \multicolumn{2}{|c|}{2013} & \multicolumn{2}{|c|}{2014} & \multicolumn{2}{|c|}{2015} \\
\hline & 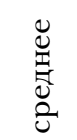 & $\begin{array}{l}\underset{\mathbb{Z}}{\mathbb{\Xi}} \\
\underset{\mathbb{Z}}{\mathbb{Z}} \\
\underset{\Xi}{\mathbb{Z}}\end{array}$ & 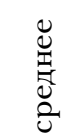 & 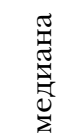 & 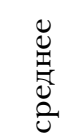 & 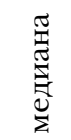 & 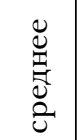 & 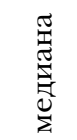 & $\begin{array}{l}\stackrel{\circlearrowright}{\mathscr{U}} \\
\underset{\mathbb{E}}{\mathbb{U}} \\
\stackrel{\tilde{U}}{u}\end{array}$ & 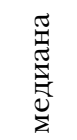 & 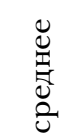 & $\begin{array}{l}\underset{\mathbb{Z}}{\mathbb{Z}} \\
\underset{\mathbb{Z}}{\mathbb{J}} \\
\stackrel{\Xi}{\Xi}\end{array}$ \\
\hline Машиностроение & 14,4 & 6,2 & 16,2 & 7,8 & 15,9 & 7,6 & 18,0 & 10,4 & 23,3 & 12,3 & 26,9 & 22,7 \\
\hline Нефтяная & 2,0 & 0,8 & 2,7 & 1,2 & 1,9 & 1,1 & 1,5 & 0,6 & 1,4 & 0,6 & 1,5 & 0,7 \\
\hline Энергетика & 0,6 & 0,2 & 1,7 & 0,8 & 1,4 & 0,9 & 1,1 & 0,8 & 3,4 & 0,5 & 2,3 & 0,8 \\
\hline $\begin{array}{l}\text { Черная } \\
\text { металлургия }\end{array}$ & 15,1 & 13,8 & 19,9 & 21,3 & 20,8 & 21,1 & 15,9 & 20,5 & 10,7 & 7,4 & 11,2 & 9,8 \\
\hline Пищевая и АПК & 9,3 & 0,3 & 10,4 & 2,1 & 12,5 & 4,1 & 1,3 & 0,5 & 8,3 & 1,6 & 12,8 & 1,6 \\
\hline Торговля & 22,2 & 7,3 & 22,4 & 7,8 & 8,2 & 1,4 & 7,7 & 2,8 & 7,1 & 2,8 & 14,8 & 1,0 \\
\hline
\end{tabular}

Большинство включенных в выборку компаний раскрывают данные о наличии / отсутствии расходов на НИОКР за отчетный год и числе патентов на ОИС на конец года в ежеквартальных и годовых отчетах, финансовой отчетности (табл. 5). В то же время ряд компаний сообщают о факте проведения НИОКР и наличии патентов, но не приводят в отчетности размеров затрат на НИОКР и полное число патентов. Поэтому мы в исследовании учитывали как абсолютное число патентов, так и дамми-переменную их наличия / отсутствия.

Если включенные в выборку нефтяные, энергетические и металлургические компании преимущественно управляются коллегиально, то среди машиностроительных, пищевых и торговых компа- 
Таблица 5

Доля компаний в выборке, раскрывших в отчетности данные о наличии/отсутствии расходов на НИОКР за год и число патентов на ОИС на конец года (2010-2015 гг.), \%

\begin{tabular}{|c|c|c|c|c|c|c|c|c|c|c|c|c|}
\hline \multirow[t]{2}{*}{ Отрасль } & \multicolumn{6}{|c|}{$\begin{array}{c}\text { Доля компаний, раскрывших рас- } \\
\text { ходы по НИОКР (либо данные по } \\
\text { их отсутствию) }\end{array}$} & \multicolumn{6}{|c|}{$\begin{array}{c}\text { Доля компаний, раскрывших число } \\
\text { патентов на конец года (либо дан- } \\
\text { ные по их отсутствию) }\end{array}$} \\
\hline & 2010 & 2011 & 2012 & 2013 & 2014 & 2015 & 2010 & 201 & 2012 & 2013 & 2014 & 2015 \\
\hline Машиностроение & 75 & 86 & 70 & 82 & 88 & 63 & 63 & 71 & 80 & 82 & 75 & 63 \\
\hline Нефтяная & 75 & 67 & 70 & 78 & 88 & 67 & 88 & 89 & 80 & 78 & 88 & 67 \\
\hline Энергетика & 67 & 73 & 72 & 80 & 100 & 90 & 60 & 73 & 61 & 73 & 89 & 60 \\
\hline $\begin{array}{l}\text { Черная } \\
\text { металлургия }\end{array}$ & 63 & 56 & 57 & 60 & 67 & 75 & 63 & 89 & 86 & 60 & 67 & 25 \\
\hline Пищевая и АПК & 57 & 100 & 100 & 75 & 100 & 75 & 57 & 50 & 60 & 75 & 86 & 75 \\
\hline Торговля & 80 & 100 & 88 & 89 & 75 & 89 & 80 & 100 & 75 & 89 & 75 & 89 \\
\hline
\end{tabular}

Таблица 6

Доля компаний в выборке с коллегиальным правлением (2010-2015 гг.), \%

\begin{tabular}{|l|c|c|c|c|c|c|}
\hline \multicolumn{1}{|c|}{ Отрасль } & 2010 & 2011 & 2012 & 2013 & 2014 & 2015 \\
\hline \hline Машиностроение & 38 & 29 & 30 & 18 & 25 & 38 \\
\hline Нефтяная & 75 & 67 & 80 & 78 & 75 & 83 \\
\hline Энергетика & 67 & 67 & 72 & 73 & 89 & 70 \\
\hline Черная металлургия & 63 & 67 & 100 & 100 & 100 & 100 \\
\hline Пищевая и АПК & 43 & 50 & 60 & 38 & 43 & 50 \\
\hline Торговля & 60 & 67 & 38 & 33 & 38 & 22 \\
\hline
\end{tabular}

ний относительно высока доля компаний с единоличным правлением (по 2015 г. $-50 \%$ и выше, табл. 6).

Аудит финансовой отчетности по стандартам МСФО и РСБУ большинства нефтяных и металлургических компаний проводят исключительно представители Big 4 (табл. 7), тогда как среди машиностроительных, пищевых и торговых компаний доля аудируемых исключительно Big 4 традиционно невысока (не превышает 38\% в период 2010-2015 гг.).

\section{4. Результаты регрессионного анализа зависимости ставки по публичному долгу от показателей ИК}

Расчеты проводились по моделям с фиксированными и со случайными эффектами.

Для зависимой переменной Ln_Spread объясняющих переменных, оказывающих значимое влияние на первом этапе отбора, несколько больше. Значимость демонстрируют переменные, построенные на основе audit, int_noncur, int_assets, RD_data, RD, patent_data, 
Таблица 7

Доля компаний в выборке, аудируемых представителями Big 4 (2010-2015), \%

\begin{tabular}{|c|c|c|c|c|c|c|c|c|c|c|c|c|}
\hline \multirow[t]{2}{*}{ Отрасль } & \multicolumn{6}{|c|}{$\begin{array}{c}\text { Доля компаний, аудируемых } \\
\text { исключительно представителями } \\
\text { Big } 4\end{array}$} & \multicolumn{6}{|c|}{$\begin{array}{c}\text { Доля компаний, одним } \\
\text { из аудиторов которых является } \\
\text { представитель Big } 4\end{array}$} \\
\hline & 2010 & 2011 & 2012 & 2013 & 2014 & 201 & 2010 & 2011 & 2012 & 2013 & 2014 & 2015 \\
\hline Машиностроение & 13 & 14 & 10 & 9 & 25 & 38 & 50 & 57 & 50 & 27 & 13 & 0 \\
\hline Нефтяная & 50 & 56 & 60 & 67 & 88 & 50 & 25 & 33 & 40 & 33 & 13 & 33 \\
\hline Энергетика & 53 & 53 & 72 & 87 & 67 & 20 & 13 & 20 & 22 & 7 & 22 & 30 \\
\hline $\begin{array}{l}\text { Черная } \\
\text { металлургия }\end{array}$ & 50 & 67 & 71 & 80 & 67 & 100 & 25 & 11 & 29 & 20 & 33 & 0 \\
\hline Пищевая и АПК & 14 & 17 & 0 & 0 & 0 & 25 & 29 & 33 & 40 & 25 & 29 & 25 \\
\hline Торговля & 0 & 0 & 0 & 0 & 0 & 11 & 80 & 100 & 50 & 67 & 63 & 44 \\
\hline
\end{tabular}

patent, directors, board, committee_compensation_data. Для объясняющих переменных int_noncur, int_assets и board это в первую очередь даммипеременные (int_noncur_dummy, int_assets_dummy и CEO_power соответственно - см. табл. 1), как и в случае с $L n \_Y T M$.

На втором этапе получены две регрессии: одна с включением $R D \_d u m m y$, другая - без нее. Это сделано потому что включение $R D \_d u m m y$ заметно уменьшает число наблюдений (не все компании отчитываются о R\&D), что, соответственно, меняет коэффициенты при

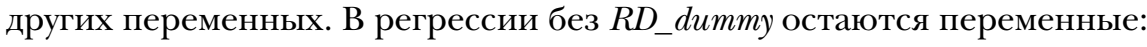
audit, int_noncur_dummy, patent_data, CEO_power. В регрессии с RD_dummy переменная patent_data также теряет значимость (см. табл. 1).

В моделях с фиксированными эффектами мы получили ожидаемый результат, что и $Y T M$, и спред к безрисковой ставке выше (при прочих равных факторах) для апреля-мая 2015 г. Значительное повышение процентных ставок и спредов обусловлено повышением ключевой ставки Банка России, ужесточением условий рефинансирования на внешних рынках капитала для российских компаний. Повышенная доходность также фиксируется для 2016 и 2014 г., пониженная - для 2011 г. Переменные CEO_power и доля государства в собственном капитале также статистически значимы и имеют отрицательный знак при коллегиальном правлении и присутствии государства ставка заимствования для компании ниже. Раскрытие информации о патентах снижает ставку заимствования.

В табл. 8 и 9 показаны результаты расчетов по моделям со случайными эффектами при разных комбинациях объясняемых переменных по тестируемым гипотезам. В табл. 9 приводятся оценки для подвыборки крупных компаний-эмитентов.

Среди факторов ИК отмечаем значимую роль НМА: при наличии НМА во внеоборотных активах YTM и Spread повышаются. То же характерно и для числа патентов (вне зависимости от показателя, 
离

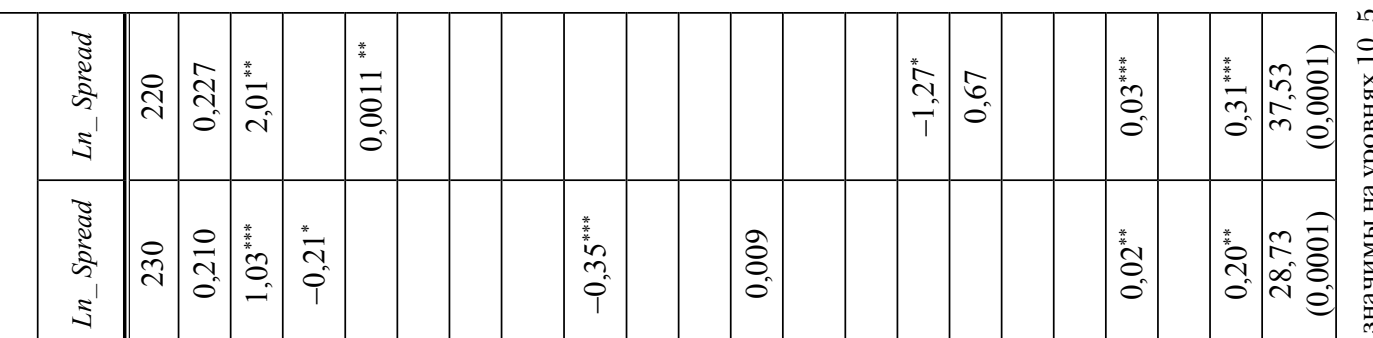

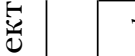

₹ H

葛

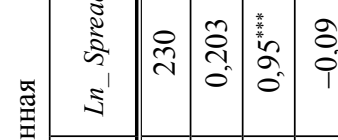

ร

בิ

$\frac{1}{0}$

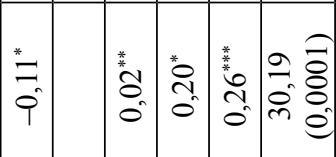

㺼

造

造 क

.

लै

○

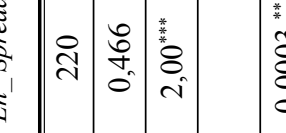

$\checkmark$

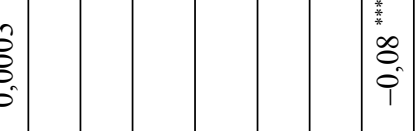

$\stackrel{*}{2} \underset{0}{-\pi}$

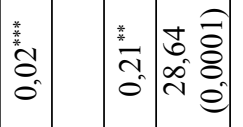

0
0
0
0
0
0

氕

표

壳

อิ

ำ

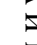

a

总

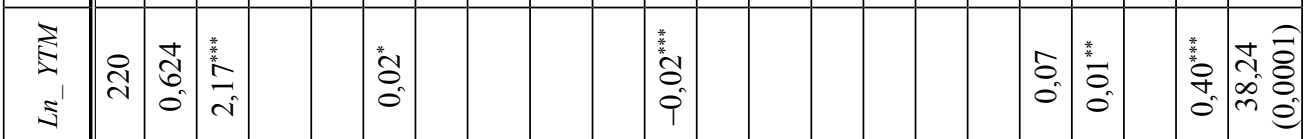

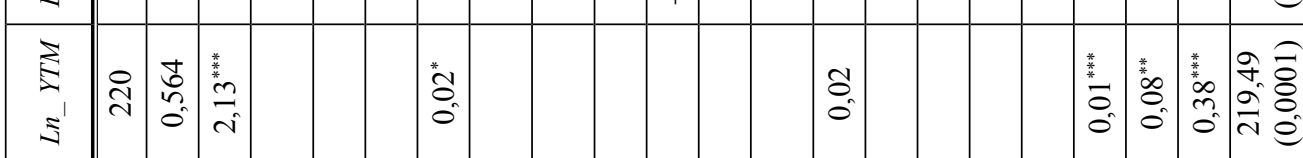

芦

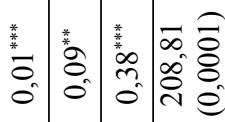
ธิ

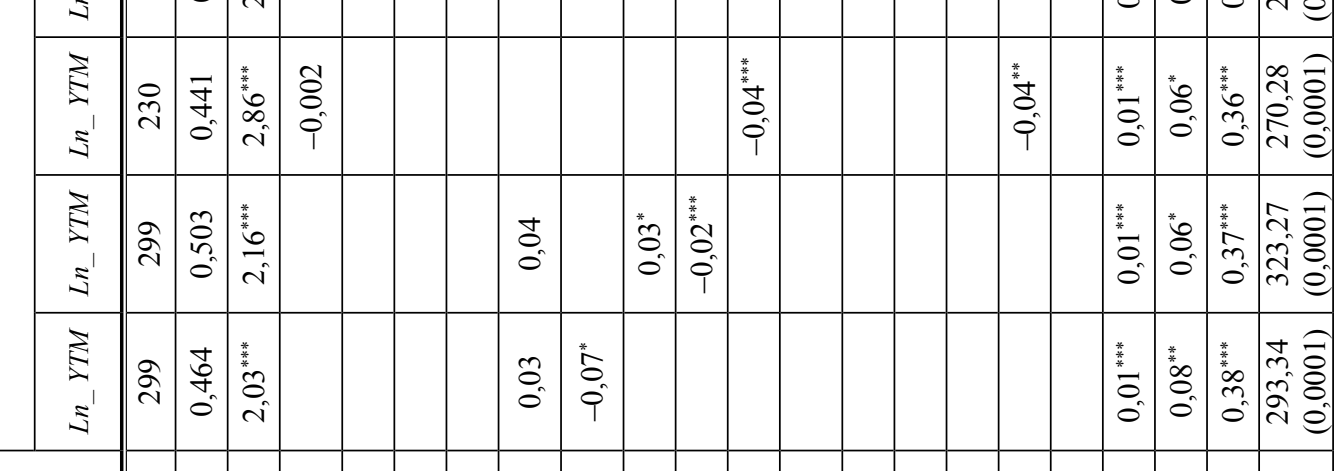
है

造



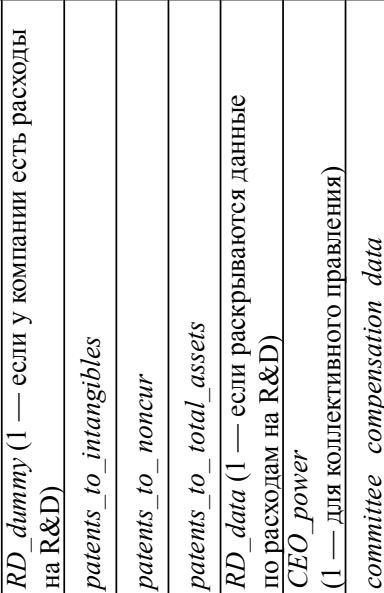

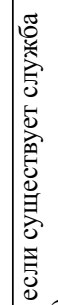

은

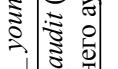
ํํㄹ है 논 蛋 要

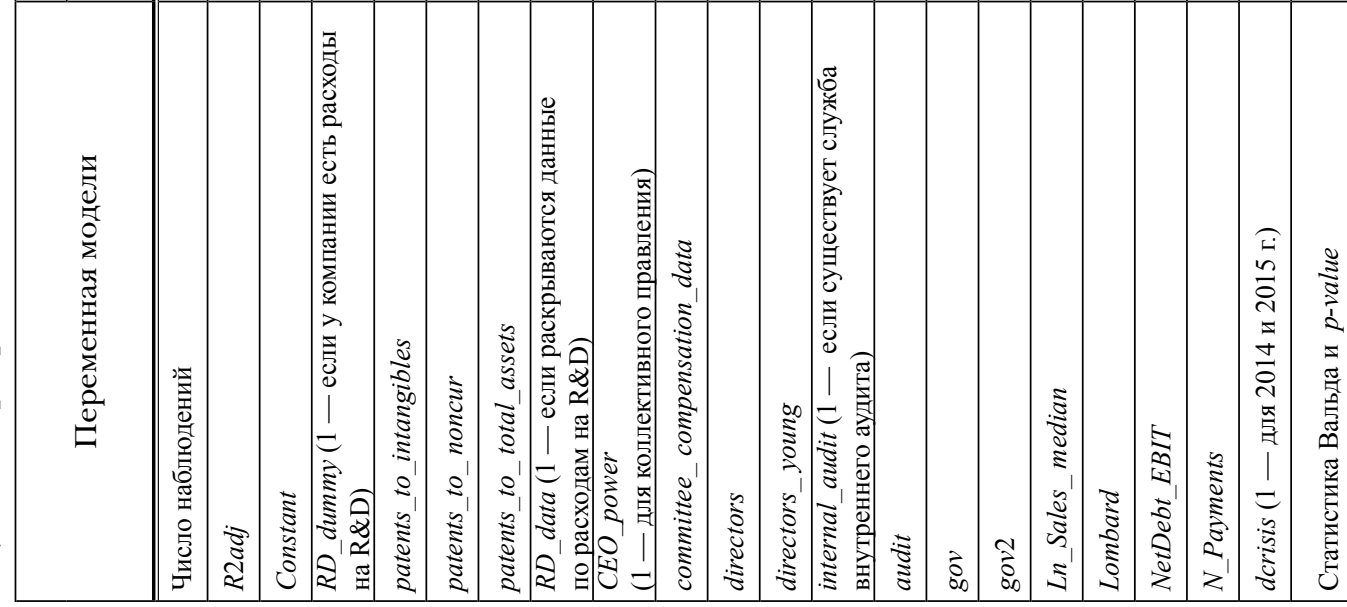
: 


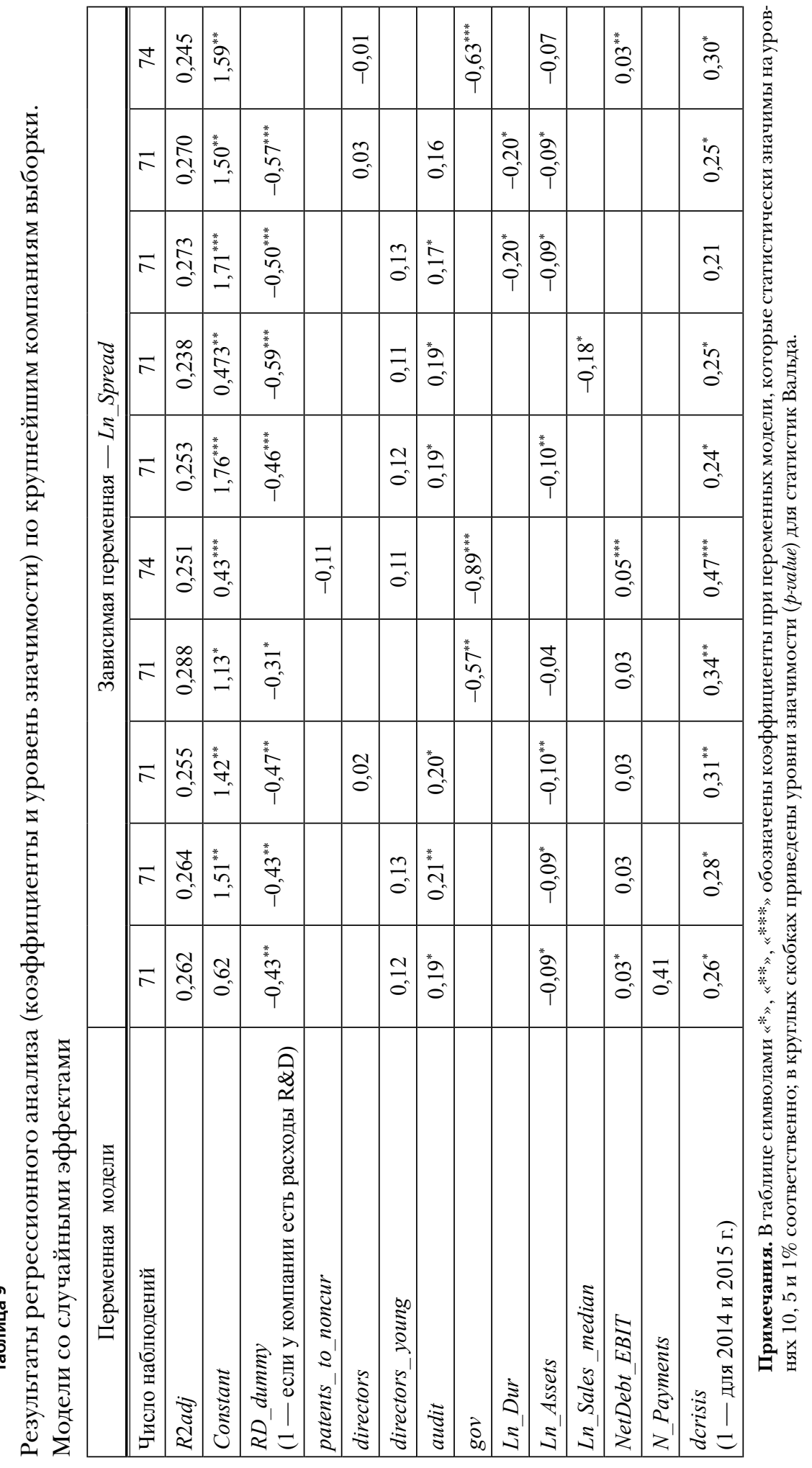


к которому нормируется число патентов, - к совокупным активам, внеоборотным активам, НМА, см. табл. 8). Это согласуется с результатами, полученными (Martins, Alves, 2010; Loumioti, 2011; Garcia-Macia, 2015) по зарубежным рынкам. Поскольку НМА характеризуются высоким уровнем риска, низким уровнем прозрачности, дорогостоящим процессом оценки, инвесторы в облигации вторичного рынка требуют более высокие премии по займам для фирм, обладающих НМА. Таким образом, балансовая стоимость НМА (см. рисунок) является плохим индикатором будущих успехов компании на рынке в части снижения стоимости заимствования. В состав НМА компании могут включать спорные по своей ценности активы, а также может иметь место эффект завышения оценки.

Если компания в нашей выборке осуществляет НИОКР, то спред YTM ниже (см. табл. 8), т.е. кредиторы рассматривают факт наличия НИОКР российских заемщиков как фактор удешевления заемного капитала. Этот вывод подтверждается на полной выборке и на подвыборке крупных компаний для дамми-переменной НИОКР (см. табл. 9). Переменная логарифма расходов на НИОКР не показала статистической значимости. Наш результат не согласуется с выводами ряда предыдущих работ (Shi, 1999; Demeulemeester, Hottenrott, 2015), где утверждается, что НИОКР повышает риск компании и ставку по займам. Отметим, что в работе (Demeulemeester, Hottenrott, 2015) pacсматривался долг фирмы в целом (не только облигации), а ставка по займам, по нашему мнению, определялась не вполне корректно (как отношение процентов, уплаченных к совокупным активам). В работе (Shi, 1999) рассматривались облигации только высокотехнологичных компаний и величина расходов на НИОКР (в нашем исследовании значимой оказалась дамми-переменная). Поэтому мы предполагаем, что завышенные расходы на НИОКР действительно порождают высокие риски, но для компаний традиционных отраслей (как в нашей выборке) само наличие НИОКР вызывает ожидания будущего роста компании и удешевляет стоимость заимствований.

Раскрытие информации о наличии патентов (patent_data) является положительным сигналом для держателей облигаций: спред YTM по облигациям снижается (но результат подтверждается только по моделям с фиксированными әффектами). Этот вывод согласуется с результатами (Orens et al., 2009) - большая степень раскрытия данных об ИК коррелирует с более низкой требуемой доходностью по собственному и заемному капиталу. Аналогичный вывод о снижении ставки собственного капитала получен в работах (Mangena et al., 2016; Boujelbene, Affes, 2013).

Влияние раскрытия информации о расходах на НИОКР $\left(R D \_d a t a\right)$ не стабильно и не значимо для большинства спецификаций моделей (см. табл. 8). Раскрытие информации о комитете по вознаграждениям увеличивает стоимость долга (см. табл. 8; 10\%-ный 
уровень значимости). Мы объясняем это тем, что данный комитет во многих российских компаниях не является полностью независимым, поэтому реакция рыночных инвесторов неположительная.

Оригинальный вывод нашей работы: в случае единоличного правления (CEO_power) стоимость публичного долга становится дороже. Данный вывод согласуется с результатами (Ashbaugh-Skaife et al., 2006): механизмы КУ, ограничивающие оппортунистическое поведение менеджеров, приносят выгоду кредиторам.

При большей численности совета директоров (переменная directors) по компаниям российского рынка мы фиксируем снижение YTM и Spread, что соответствует выводам (Anderson et al., 2004). Большая численность совета директоров позволяет лучше учесть разные мнения и применять более широкие компетенции при разработке стратегии, что снижает риски кредиторов и удешевляет долговое финансирование. Мы не выявили стабильного значимого влияния возраста членов совета директоров на YTM и спред по рублевым КО: переменная directors меняет направление влияния в разных спецификациях моделей (см. табл. 8). Данный вывод согласуется с результатами (Anderson et al., 2004). Для крупных компаний по этой переменной получен более интересный вывод (см. ниже).

В работе тестировалось несколько спецификаций моделей с переменными, характеризующими долю государства в капитале компании. В частности, в табл. 8 показаны модели, где присутствуют одновременно доля государства в акционерном капитале (gov) и ее квадрат (gov2). Результаты расчетов показали, что при учете нелинейности (gov2) влияние переменной gov статистически значимое и отрицательное, а влияние переменной gov 2 - положительное. Мы делаем вывод, что стоимость публичного долга нелинейно связана с долей государства. Небольшое увеличение доли государства в капитале компании снижает ставку по облигациям, а дальнейшее увеличение, напротив, приводит к ее росту ( $U$-образная форма, ветви вверх). Такая нелинейность не противоречит ранее полученным выводам относительно рыночной стоимости бизнеса. Высокий уровень контроля государства может породить для кредиторов риски изъятия (перенаправления) денежных средств компании на решение тех или иных государственных задач.

Таким образом, подтвердились гипотезы нашего исследования относительно значимого влияния на требуемую доходность публичного займа следующих элементов организационного (инновационного и процессного) ИК: доли НМА во внеоборотных активах (и в совокупных активах), числа патентов, проведения НИОКР, фиксируемого по наличию затрат, признака коллегиального / единоличного правления, численности совета директоров.

По контрольным объясняющим переменным мы делаем следующие выводы: размер компании значимо (на 1\%-ном уровне) и отри- 
цательно влияет на YTM и на Spread (см. табл. 8). В регрессиях с отраслевыми дамми значим показатель долговой нагрузки ICR. Стоимость заимствования снижается при увеличении коэффициента покрытия процентов. В регрессиях со случайными эффектами значимое (на $5 \%$-ном уровне) положительное влияние на стоимость долга оказывает Net Debt / EBIT (см. табл. 8). Полученные выводы согласуются с результатами предыдущих исследований (Teplova, Sokolova, 2015; Теплова, Соколова, 2011).

В моделях с отраслевыми дамми в объяснении различий в спреде YTM значима отраслевая принадлежность: для пищевых, машиностроительных, металлургических компаний спред YTM значимо выше, чем для нефтегазовых (см. табл. 8).

Мы также протестировали модели со случайными эффектами по подвыборке, состоящей из трети наиболее крупных компаний (ранжирование проведено по выручке, результаты показаны в табл. 9). Для болышинства переменных выводы остаются прежними, но есть и отличия. Как и для выборки в целом, наличие расходов на НИОКР повышает ожидания инвесторов относительно будущего роста и снижает стоимость долга. Информация по патентам перестает играть сигнальную роль для рыночных инвесторов. В отличие от выборки в целом, для крупнейших компаний влияние числа членов совета директоров становится нестабильным и незначимым. Доля молодых директоров увеличивает стоимость долга, но статистическая значимость низка. Возможно, молодые директора более склонны к риску и кредиторы принимают это во внимание. Аудит отчетности, осуществляемый представителями Big 4, увеличивает YTM и спред. Мы объясняем это тем, что топ-менеджмент крупнейших компаний может оказывать влияние на локальных (национальных) аудиторов с целью представления лучших финансовых результатов. Аудиторы Big 4 более объективны. Топ-менеджеры крупнейших российских компаний не могут оказывать на них давления. Объективное раскрытие обнаруженных проблем в отчетности повышает риски кредитования в глазах держателей облигаций.

Закономерный результат - размер компании важен, а долговая нагрузка учитывается кредиторами меньше, т.е. держатели облигаций учитывают принцип «too big to fail». Для рассматриваемой подвыборки (см. табл. 9) компании с бо́льшими совокупными активами и выручкой имеют более низкую стоимость долга. Коэффициент долговой нагрузки Net Debt / EBIT положительно влияет на спреды доходности облигаций, но статистическая значимость на $10 \%$-ном уровне наблюдается лишь в ряде спецификаций моделей (для выборки в целом влияние положительное и значимое). Мы объясняем это тем, что стандартное отклонение данного коэффициента намного выше для всей выборки, чем для подвыборки крупнейших компаний (6,3 и 4,4 соответственно). 


\section{Заключение}

В нашей работе представлены результаты анализа зависимости требуемой доходности по публичным заимствованиям российских нефинансовых компаний от элементов инновационного и процессного ИК. В качестве зависимых переменных рассматривались показатели YTM и спред к безрисковой ставке (Spread) облигаций вторичного рынка. Исследование проводилось для широкой выборки компаний реального сектора в период 2010-2015 гг. (всего 299 наблюдений).

Вклад нашего исследования заключается в использовании широкой линейки элементов ИК и получении новых эмпирических знаний о роли ИК в удешевлении долга на российском рынке.

Среди рассматриваемых нами элементов ИК значима роль HМА: при наличии НМА во внеоборотных активах доходность КО и спред повышаются. Мы это объясняем тем, что наличие НМА (как накопленных, отраженных по затратам в прошлом активов) воспринимается рыночными инвесторами как индикатор повышенного риска компании из-за возможных проблем достоверности оценки, низкой прозрачности качества этих активов. Для рыночных инвесторов рост таких активов не гарантирует роста финансовой устойчивости и возможности возмещения займа в случае банкротства компании или дефолта по облигационному выпуску.

Детальное рассмотрение элементов НМА, выделение тех, которые сигнализируют о наличии будущих денежных потоков и конкурентных преимуществах компании, позволило сделать вывод о распознавании держателями облигаций российского рынка выгод наращения ИК. Раскрытие информации о наличии патентов важно в формировании ставок доходности.

По нашей выборке кредиторы рассматривают факт наличия НИОКР российских заемщиков как фактор удешевления заемного капитала. Мы рассматриваем этот результат как оценку сигнального эффекта формирования заделов на будущие денежные выгоды. В отличие от НМА расходы на НИОКР фиксируются по одному предыдущему году и не несут ошибок прошлых лет, а также формируют ожидания будущих конкурентных преимуществ.

Оригинальный вывод нашего исследования - единоличное правление приводит к удорожанию публичного долга. Увеличение численности совета директоров приводит к выработке сбалансированной стратегии и распознается рыночными инвесторами, ставки по облигациям вторичного рынка КО становятся ниже. 
রц!...pY

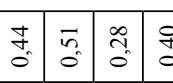$$
\text { (: }
$$

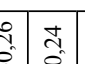

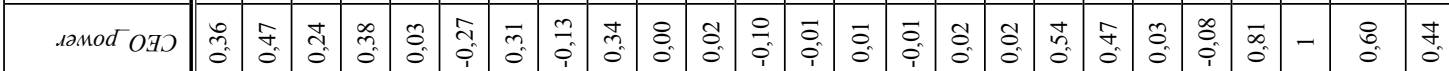

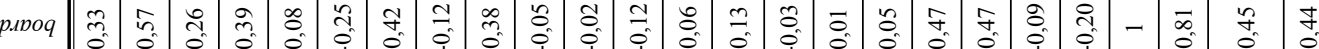

цазал

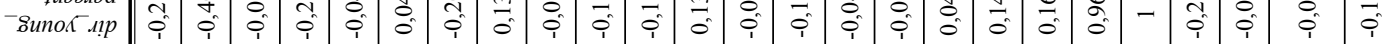

\begin{tabular}{|c|c|c|c|c|c|c|c|c|c|c|c|c|c|c|c|c|c|c|c|c|c|c|c|c|c|c|c|}
\hline 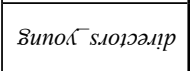 & i & & $\begin{array}{l}\overrightarrow{0} \\
i\end{array}$ & $\stackrel{7}{i}$ & $\overbrace{0}^{0}$ & & & & : & & $\frac{a}{i}$ & & & & & & & & & & & & & & & & \\
\hline
\end{tabular}

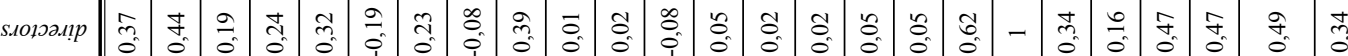

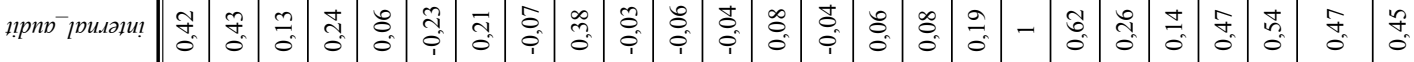

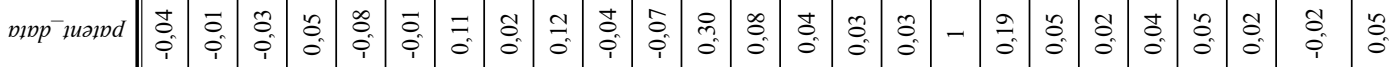

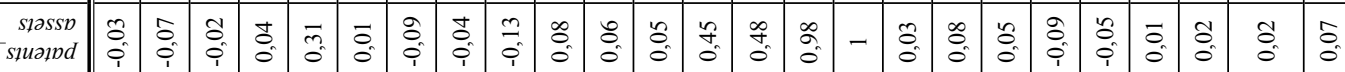

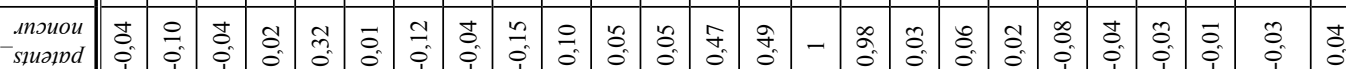

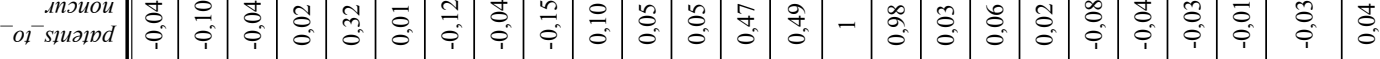

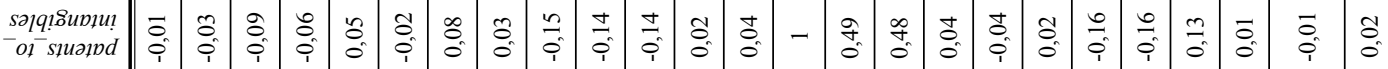

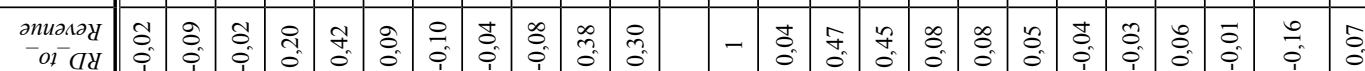

${ }^{-}{ }^{-}$dy

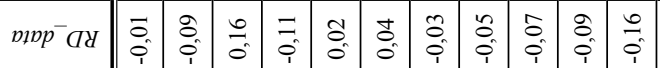

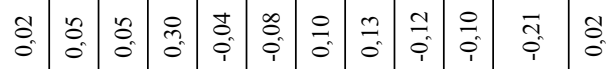

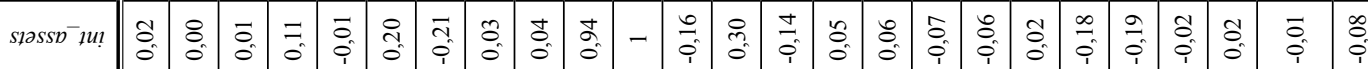

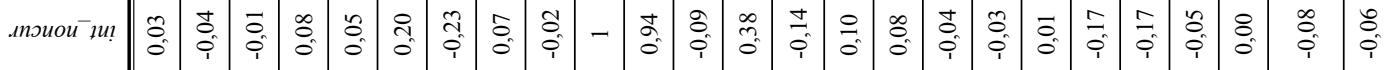

要

!pno

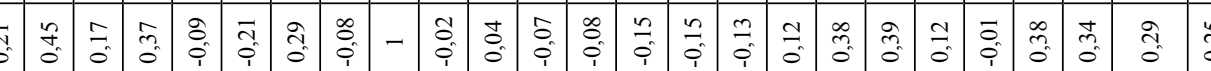

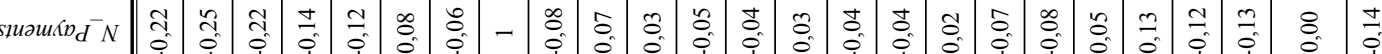

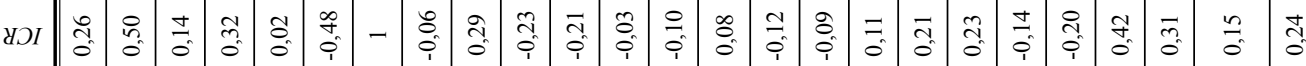

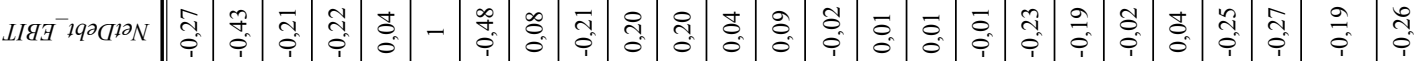

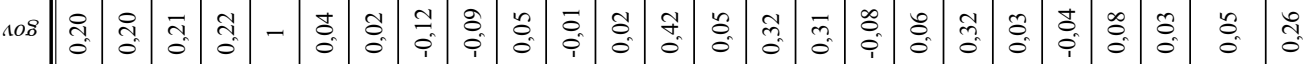

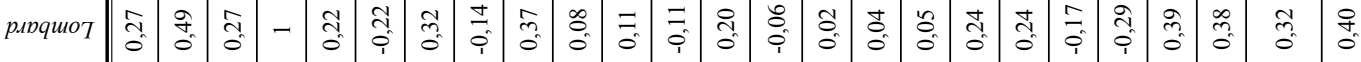

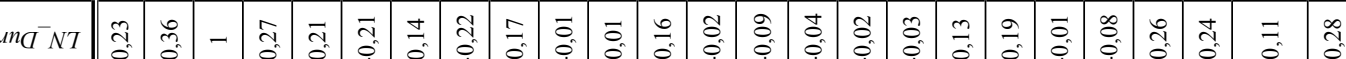

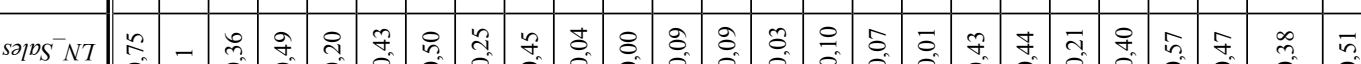

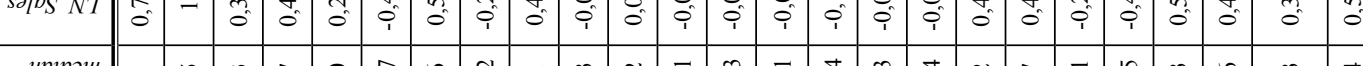

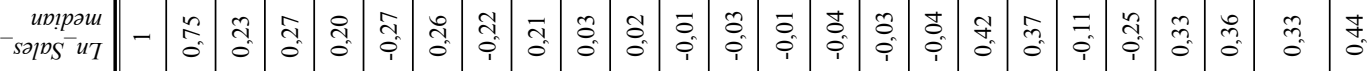

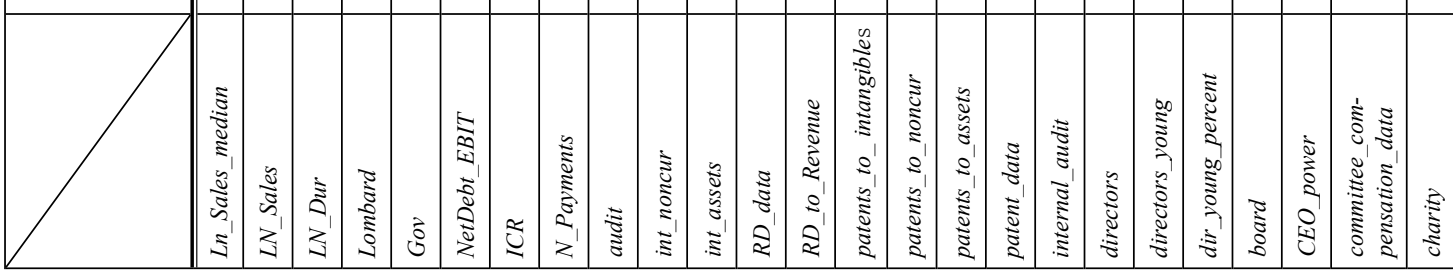




\section{ЛИТЕРАТУРА}

Милицкова Т.М. (2013). Влияние специфических факторов на спреды доходности корпоративных облигаций / / Корпоративные финансы. № 2 (26). C. $50-70$.

Сувейка Ш.М. (2016). Шоки спреда доходности на быстрорастущих рынках облигаций: роль волатильности // Финансовый бизнес. № 1 (180). C. 59-66.

Теплова Т.В. (2007). Специфические риски компании и стоимость заимствований / / Сибирская финансовая школа (Аваль). № 3. С. 61-68.

Теплова Т.В., Соколова Т.В. (2011). Моделирование стоимости корпоративного заимствования на российском рынке // Управление корпоративными финансами. Т. 5. № 47. С. 198-220.

Эдвинссон Л. (2005). Корпоративная долгота: Навигация в экономике, основанная на знаниях. М.: ИНФРА-М.

Al-Najjar B., Taylor P. (2008). The Relationship between Capital Structure and Ownership Structure - New Evidence from Jordanian Panel Data // Managerial Finance. Vol. 34 (2). P. 919-933.

Alves S., Martins J. (2009). The Impact of Intangible Assets on Financial and Governance Policies: A Univariate Analysis // Corporate Ownership and Control. Vol. 7. P. 416-433.

Alves S., Martins J. (2010). The Impact of Intangible Assets on Financial and Governance Policies: UK Evidence / / International Research Journal of Finance and Economics. Vol. 36. P. 147-169.

Anderson R.C., Mansi S.A., Reeb D.M. (2004). Board Characteristics, Accounting Report Integrity, and the Cost of Debt / / Journal of Accounting and Economics. Vol. 37 (3). P. 315-342.

Ashbaugh-Skaife H., Collins D.W., LaFond R. (2006). The Effects of Corporate Governance on Firms' Credit Ratings / / Journal of Accounting and Economics. Vol. 42 (1-2). P. 203-243.

Boujelbene M.A., Affes H. (2013). The Impact of Intellectual Capital Disclosure on Cost of Equity Capital: A Case of French Firms / / Journal of Economics, Finance and Administrative Science. Vol. 18 (34). P. 45-53.

Chan K.C., Lakonishok J., Sougiannis T. (2001). The Stock Market Valuation of Research and Development Expenditure // Journal of Finance. Vol. 56 (6). P. 2431-2456.

Chiao C. (2002). Relationship Between Debt, R\&D and Physical Investment, Evidence from US Firm-Level Data / / Applied Financial Economics. Vol. 12. P. 105-121.

Demeulemeester S., Hottenrott H. (2015). R\&D Subsidies and Firms' Cost of Debt. Dusseldorf Institute for Competition Economics. Discussion Paper 201.

Garcia-Macia D. (2015). The Financing of Ideas and the Great Deviation. SIEPR Discussion Paper, 16-012.

Griliches Z. (ed.) (1984). R\&D, Patents and Productivity. Chicago: The University of Chicago Press and NBER.

Hall B.H., Jaffe A.B., Trajtenberg M. (2005). Market Value and Patent Citations // Rand Journal of Economics. Vol. 36. P. 16-38. 
Iatridis G.E., Senftlechner D. (2014). An Empirical Investigation of Goodwill in Austria: Evidence on Management Change and Cost of Capital / / Australian Accounting Review. Vol. 69 (24). P. 171-181.

Johnson S.G., Schnatterly K., Hill A.D. (2013). Board Composition beyond Independence: Social Capital, Human Capital, and Demographics // Journal of Management. Vol. 39 (1). P. 232-262.

La Rosa F., Liberatore G. (2014). Biopharmaceutical and Chemical Firms' R\&D Disclosure, and Cost of Equity: The impact of the Regulatory Regime // European Management Journal. Vol. 32. P. 806-820.

Lev B. (2001). Intangibles: Management, Measurement and Reporting. Washington: Brookings Institution Press.

Lev B. (1992). Information Disclosure Strategy // California Management Review. Vol. 34. P. 9-32.

Lev B., Sougiannis T. (1999). Penetrating the Book-to-Market Black Box: The R\&D Effect / / Journal of Business Finance and Accounting. Vol. 26. P. 419-449.

Liu Q., Wong K.P. (2011). Intellectual Capital and Financing Decisions: Evidence from the U.S. Patent Data / / Management Science. Vol. 57 (10). P. 1861-1878.

Lorca C., Sanchez-Ballesta J.P., Garcia-Meca E. (2011). Board Effectiveness and Cost of Debt / / Journal of Business Ethics. Vol. 100 (4). P. 613-631.

Loumioti M. (2011). The Use of Intangible Assets as Loan Collateral. SSRN 1748675. Macagnan C.B. (2009). Voluntary Disclosure of Intangible Resources and Stock Profitability / / Intangible Capital. Vol. 5 (1). P. 1-32.

Mangena M., Li J., Tauringana V. (2016). Disentangling the Effects of Corporate Disclosure on the Cost of Equity Capital: a Study of the Role of Intellectual Capital Disclosure / / Journal of Accounting, Auditing and Finance. Vol. 31 (1). P. 3-27.

Martins J., Alves S. (2010). The Impact of Intangible Assets on Financial and Governance Policies: a Literature Review / / Portuguese Journal of Management Studies. Vol. XV (1). P. 87-107.

Orens R., Aerts W., Lybaert N. (2009). Intellectual Capital Disclosure, Cost of Finance and Firm Value / / Management Decision. Vol. 47 (10). P. 1536-1554.

Patel S., Dallas G. (2002). Transparency and Disclosure: Overview of Methodology and Study Results-United States. Working paper, Standard and Poor's and SSRN. [Электронный ресурс] Режим доступа: http:/ / ssrn.com/abstract=422800, свободный. Загл. с экрана. Яз. англ. (дата обращения: август 2017 г.).

Salawu R.O., Agboola A.A. (2008). The Determinants of Capital Structure of Large Non-Financial Listed Firms in Nigeria // Journal of Business and Finance Research. Vol. 2 (2). P. 75-84.

Shi C. (1999). On the Trade-off between the Future Benefits and Riskiness of R\&D: A Bondholders' Perspective. Working Paper, University of California-Irvine School of Business, Irvine, C.A.

Teplova T.V., Sokolova T.V. (2015). Bond Liquidity Indicators: Can New Thomson Reuters Indices Explain Difference in Bond Returns? / / Journal of Applied Economic Sciences. Vol. X. No. 6 (36). P. 897-913.

Wang H., Liang P., Li H., Yang R. (2016). Financing Sources, R\&D Investment and Enterprise Risk / / Procedia Computer Science. Vol. 91. P. 122-130. 


\section{REFERENCES (with English translation or transliteration)}

Al-Najjar B., Taylor P. (2008). The Relationship between Capital Structure and Ownership Structure - New Evidence from Jordanian Panel Data. Managerial Finance, 34 (2), 919-933.

Alves S., Martins J. (2009). The Impact of Intangible Assets on Financial and Governance Policies: A Univariate Analysis. Corporate Ownership and Control, 7, $416-433$.

Alves S., Martins J. (2010). The Impact of Intangible Assets on Financial and Governance Policies: UK Evidence. International Research Journal of Finance and Economics, $36,147-169$.

Anderson R.C., Mansi S.A., Reeb D.M. (2004). Board Characteristics, Accounting Report Integrity, and the Cost of Debt. Journal of Accounting and Economics, 37(3), 315-342.

Ashbaugh-Skaife H., Collins D.W., LaFond R. (2006). The Effects of Corporate Governance on Firms' Credit Ratings. Journal of Accounting and Economics, 42 (1-2), 203-243.

Boujelbene M.A., Affes H. (2013). The Impact of Intellectual Capital Disclosure on Cost of Equity Capital: A Case of French Firms. Journal of Economics, Finance and Administrative Science, 18 (34), 45-53.

Chan K.C., Lakonishok J., Sougiannis T. (2001). The Stock Market Valuation of Research and Development Expenditure. Journal of Finance, 56(6), 2431-2456.

Chiao C. (2002). Relationship Between Debt, R\&D and Physical Investment, Evidence from US Firm-Level Data. Applied Financial Economics, 12, 105-121.

Demeulemeester S., Hottenrott H. (2015). R\&D Subsidies and Firms' Cost of Debt. Dusseldorf Institute for Competition Economics. Discussion Paper 201.

Edvinsson L. (2005). Corporate Longitude: Navigating the Knowledge Economy. Moscow: INFRA-M (in Russian).

Garcia-Macia D. (2015). The Financing of Ideas and the Great Deviation. SIEPR Discussion Paper, 16-012.

Griliches Z. (ed.). (1984). R\&D, Patents and Productivity. Chicago: The University of Chicago Press and NBER.

Hall B.H., Jaffe A.B., Trajtenberg M. (2005). Market Value and Patent Citations. Rand Journal of Economics, 36, 16-38.

Iatridis G.E., Senftlechner D. (2014). An Empirical Investigation of Goodwill in Austria: Evidence on Management Change and Cost of Capital. Australian Accounting Review, 69 (24), 171-181.

Johnson S.G., Schnatterly K., Hill A.D. (2013). Board Composition beyond Independence: Social Capital, Human Capital, and Demographics. Journal of Management, 39 (1), 232-262.

La Rosa F., Liberatore G. (2014). Biopharmaceutical and Chemical Firms' R\&D Disclosure, and Cost of Equity: The impact of the Regulatory Regime. European Management Journal, 32, 806-820.

Lev B. (1992). Information Disclosure Strategy. California Management Review, 34, 9-32.

Lev B. (2001). Intangibles: Management, Measurement and Reporting. Washington: Brookings Institution Press. 
Lev B., Sougiannis T. (1999). Penetrating the Book-to-Market Black Box: The R\&D Effect. Journal of Business Finance and Accounting, 26, 419-449.

Liu Q., Wong K.P. (2011). Intellectual Capital and Financing Decisions: Evidence from the U.S. Patent Data. Management Science, 57 (10), 1861-1878.

Lorca C., Sanchez-Ballesta J.P., Garcia-Meca E. (2011). Board Effectiveness and Cost of Debt. Journal of Business Ethics, 100 (4), 613-631.

Loumioti M. (2011). The Use of Intangible Assets as Loan Collateral. SSRN 1748675.

Macagnan C.B. (2009). Voluntary Disclosure of Intangible Resources and Stock Profitability. Intangible Capital, 5 (1), 1-32.

Mangena M., Li J., Tauringana V. (2016). Disentangling the Effects of Corporate Disclosure on the Cost of Equity Capital: a Study of the Role of Intellectual Capital Disclosure. Journal of Accounting, Auditing and Finance, 31 (1), 3-27.

Martins J., Alves S. (2010). The Impact of Intangible Assets on Financial and Governance Policies: a Literature Review. Portuguese Journal of Management Studies, XV (1), $87-107$.

Militskova T.M. (2013). The Impact of Specific Determinants on Corporate Bond Yield Spreads. Journal of Corporate Finance Research, 2 (26), 50-70 (in Russian).

Orens R., Aerts W., Lybaert N. (2009). Intellectual Capital Disclosure, Cost of Finance and Firm Value. Management Decision, 47 (10), 1536-1554.

Patel S., Dallas G. (2002). Transparency and Disclosure: Overview of Methodology and Study Results-United States. Working paper, Standard and Poor's and SSRN. Available at: http://ssrn.com/abstract=422800 (accessed: August 2017).

Salawu R.O., Agboola A.A. (2008). The Determinants of Capital Structure of Large NonFinancial Listed Firms in Nigeria. Journal of Business and Finance Research, 2 (2), $75-84$.

Shi C. (1999). On the Trade-off between the Future Benefits and Riskiness of R\&D: A Bondholders' Perspective. Working Paper. University of California-Irvine School of Business, Irvine, C.A.

Suveyka S.M. (2016). Emerging Markets Corporate Bond Spread Shocks: the Role of Volatility. Financial Business, 1(180), 59-66 (in Russian).

Teplova T.V. (2007). Specific Risks of the Company and the Cost of Borrowing. Siberian Financial School (Aval), 3, 61-68 (in Russian).

Teplova T.V., Sokolova T.V. (2011). Modeling Cost of Corporate Debt in the Russian Market. Management of Corporate Finance, 5, 47, 198-220 (in Russian).

Teplova T.V., Sokolova T.V. (2015). Bond Liquidity Indicators: Can New Thomson Reuters Indices Explain Difference in Bond Returns? Journal of Applied Economic Sciences, X, 6 (36), 897-913.

Wang H., Liang P., Li H., Yang R. (2016). Financing Sources, R\&D Investment and Enterprise Risk. Procedia Computer Science, 91, 122-130.

Received 20.01.2017 
T.V. Teplova

National Research University Higher School of Economics,

Moscow, Russia

T.V. Sokolova

National Research University Higher School of Economics, Moscow, Russia

\title{
A.S. Teplov \\ State University of Management, Moscow, Russia \\ Intellectual Capital of Russian Companies as a Driver of Reducing the Cost of Debt ${ }^{2}$
}

\begin{abstract}
In the 21st century intellectual capital (IC) is considered as a source of competitive advantages and as a factor increasing the enterprise value. The question about the significance of IC for reducing the cost of debt in the Russian market is still open. Our paper is devoted to the identification of the process and innovative IC indicators signalizing financial benefits. We consider the transparent and market element of debt - corporate bonds outstanding. The sample consists of 299 observations on 93 Russian companies of the non-financial sector in the period from 2010 to 2015. We use the method of regression analysis on the unbalanced panel. Our empirical research showed that firms have an opportunity to reduce the cost of debt by increasing elements of IC. IC elements affect the cost of publicly traded debt differently. The following factors have a significant impact on bond yields: indicators of intangible assets, R\&D expenses, the composition of a team of managers, the size of the Board of directors. Possession of intangible assets and an increase in the number of patents raises yields of quoted corporate bonds. Existence of R\&D for Russian companies is a positive signal for creditors - yields of corporate bonds decline. The original conclusion of our study - sole executive body leads to an increase in the cost of public debt. The greater size of the Board of directors contributes to the development of a balanced strategy and is recognized by market investors: yields of outstanding corporate bonds become lower.
\end{abstract}

Keywords: intellectual capital; intangible assets; cost of debt; ruble corporate bonds; bond yield to maturity (YTM).

JEL Classification: O34, G12.

\footnotetext{
${ }^{2}$ The publication was prepared within the framework of the Academic Fund Program at the National Research University Higher School of Economics (HSE) in 2017-2018 (grant No. 18-05-0007) and by the Russian Academic Excellence Project "5-100".
} 